\title{
Joseph Heitman receives the 2018 ASCI/Korsmeyer Award
}

$\mathbf{T}_{\mathrm{h}}$ he American Society for Clinical Investigation has selected Joseph Heitman of Duke University as its 2018 recipient of the Stanley J. Korsmeyer Award, for his pioneering research in fungal genetics and outstanding mentorship. As a young postdoctoral fellow, Heitman's passion and creativity was instrumental in the initial discovery of TOR in Michael Hall's lab, as recently described $(1,2)$. Throughout his career, Heitman (Figure 1) cultivated collaborative research projects and encouraged his trainees to explore new research directions, leading his lab to make innovative and unexpected discoveries in fungal pathogenesis, sexual cycles, and evolutionary biology. The JCI recently met with Dr. Heitman to discuss his expansive body of work.

JCI: What inspired you to pursue a combined $\mathrm{MD} / \mathrm{PhD}$ degree?

Heitman: I was a chemistry/biochemistry dual major as an undergraduate at the University of Chicago. They had a special BS/MS program to pursue undergraduate and graduate education simultaneously. I was taking organic chemistry in my second year of college, and in the spring quarter, if you did well in the course, they would place you into a real organic chemistry laboratory instead of doing the regular lab associated with the course. That was the first of three formative lab experiences as an undergraduate. While working in Joe Fried's lab, I met two MD/PhD students, Pui Kwok and George Ebert, and their example inspired me to pursue a similar career trajectory.

I joined the $\mathrm{MD} / \mathrm{PhD}$ program of Cornell and Rockefeller Universities originally intending to study chemistry and design DNA binding proteins, but I completely switched directions when I arrived at graduate school. I worked on bacterial genetics, studying responses to DNA damage - how cells can survive single-stranded and double-stranded breaks in DNA and how proteins and enzymes recognize specific DNA sequences.

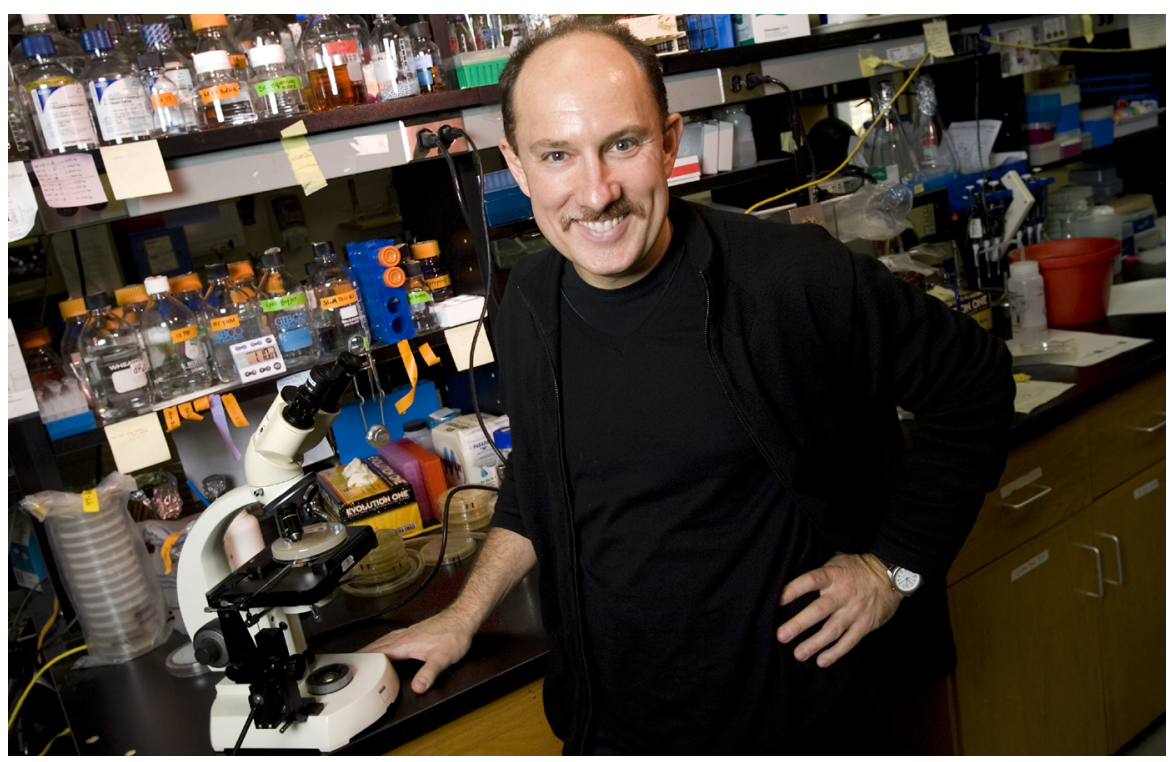

Figure 1. Joseph Heitman will be honored with the 2018 ASCI/Stanley J. Korsmeyer Award.

JCI: You had an unusual trajectory in that you took a postdoctoral position before you finished your MD degree.

Heitman: As I was finishing my $\mathrm{PhD}$, I went to Cold Spring Harbor and took the yeast genetics course, thinking that I would go one step up from a prokaryotic model organism to a eukaryotic model, and I just fell in love with yeast as a model system. I realized that I was more excited and passionate about research and I didn't feel ready to go back and continue medical training, so I took a leave of absence for two years and went to Switzerland as a postdoctoral fellow at the University of Basel in Michael Hall's lab.

JCI: It was in Hall's lab that you, in collaboration with Rao Movva, discovered the genes encoding TOR in yeast.

Heitman: I went there to work on a very different kind of project, which was to try to understand how proteins are imported into the nucleus. At that time, nuclear localization signals had been identified, but there was no idea at a mechanistic level how this translated into a protein being imported into the nucleus. We had designed and were conducting a genetic screen to elucidate these pathways, but were not obtaining the results or mutants we sought. Instead, we kept finding mutations in the pheromone response pathway, which is a canonical signal transduction pathway.

I began reading about signal transduction pathways. Many investigators were studying receptors on the cell surface, and many others were studying transcription factors in the nucleus, but few were focusing on how the pathway carried information through the cytoplasm and into the nucleus. We had the idea that we could use some drugs to probe this. I came upon a paper from Max Tropschug about cyclosporine's mechanism of action in the fungus Neurospora crassa, and I thought we could adopt a similar approach in Saccharomyces cerevisiae (3). I returned to the lab telling Mike that I thought this would be an exciting direction. It turned out that Mike had been hired as a consultant by Rao Movva at Sandoz, who independently had similar ideas and had identified a cyclosporine-binding protein from Saccharomyces. Rao and I met, discussed the projects, and started collaborating, essentially that day. Ultimately, our pharmaacademia collaboration led to the dis- 
covery of TOR as the target of rapamycin using a yeast genetics approach.

JCI: Once you set up your own lab, how did you pivot to fungal pathogenesis research?

Heitman: I finished medical school in June of 1992, and arrived at Duke in September. The lab was established to capitalize on yeast as a model to elucidate targets of immunosuppressive drugs and their mechanisms of action. I had begun reading about infectious disease while I was a postdoctoral fellow, because when immunosuppressive drugs are given to patients, they often suffer infectious complications. I had been thinking for some time that it would be both fascinating and important to work on a pathogen. I just didn't have an entry point. Then my phone rang one day and it was John Perfect, who is a champion and leader in the field of fungal pathogens. He himself had attended the Cold Spring Harbor yeast genetics course the year before me and decided he would establish genetic approaches for Cryptococcus.

John knew that if he treated patients with cyclosporine, they often developed cryptococcal meningitis, yet there were papers at the time by Chris Mody and colleagues showing that cyclosporine exhibits very potent antifungal activity in a petri dish (4). John asked why isn't cyclosporine protecting patients from cryptococcal infections if this drug is antifungal in vitro. This question was directly related to the focus of our own research and a logical starting point. After my first visit with John, I returned to the lab with a petri dish of $\mathrm{H} 99$, the canonical lab reference strain of Cryptococcus.

John not only provided a rationale for working on Cryptococcus, he sent me two people. One was an undergraduate, Audrey Odom, who is now on the faculty at Washington University and a leader in malaria research, and the other was a medical fellow, Andrew Alspaugh, who is now a professor at Duke in the infectious diseases division. This formed a group within the group working in a completely new direction, and the studies they conducted set the stage for much that followed $(5,6)$.

JCI: How did you become interested in understanding the sexual cycles of Cryptococcus?

Heitman: Part of it was scientific, and part of it was practical. We were seeking $\mathrm{NIH}$ funding for the Cryptococcus work, and I had submitted an R01 grant that went through three rounds and just missed getting funded, even though the NIH was clamoring for Saccharomyces geneticists who would switch to work on fungal pathogens. After that, I wrote two more R01 grants, one in response to a request for applications on antifungal drug development, in the span of a couple of weeks. With some luck, and advocacy at Council by the mycology program officer, Dennis Dixon, all three grants were funded simultaneously. We went from no NIH support on the project to having three concurrent R01 grants, and as a consequence the size of the lab doubled and a suite of talented students and fellows was recruited to focus on Cryptococcus.

Given the time that I had spent thinking about the Saccharomyces pheromone response pathway and its sexual cycle, I found myself interested in the Cryptococcus mating-type locus and how the pathways were controlled. There were some previous studies on Cryptococcus from June Kwon-Chung and Jef Edman, but much was completely unknown. Fungi, like animals, come in two different sexes or mating types, and in a sexually reproducing population, the mating types are often in equilibrium. But for the globally distributed serotype A isolates of Cryptococcus, there was a conundrum; the vast majority of the isolates are mating-type $\alpha$. Of several thousand naturally occurring isolates, only three were of the rare a-mating-type, and their ability to mate was limited. Thus, it wasn't clear where or how the sexual cycle was occurring or how. It turns out there are two explanations: 1 ) there are lineages in sub-Saharan Africa in which the other mating type is more common and bisexual reproduction occurs, and 2) some isolates don't require a mating partner of opposite mating type, and can mate on their own in a process called unisexual reproduction. In fungi, this is a form of selfing called homothallism; in animals, an analogous form of self-fertility is called parthenogenesis.

JCI: From your work on the sexual cycles of Cryptococcus, you started exploring the evolutionary implications of a single mating type. It's very striking that you so often have been able to take a broader view of your research.

Heitman: When I first came to Duke, I was a self-described myopic yeast geneti- cist. You sort of have your blinders on, focusing on one small area, trying to avoid distraction. Then I started working on a pathogenic yeast. Suddenly, I had two organisms to study and that became a slippery slope.

Another inflection point was meeting Rytas Vilgalys, a mycologist from the Department of Biology at Duke. Rytas convinced one of his students, Tim James, to have me on his $\mathrm{PhD}$ thesis committee. Tim worked on the evolution of the mating-type locus in basidiomycetes and the transitions between out-crossing and in-breeding, which we call heterothallism and homothallism. I was approaching it as a naive yeast geneticist and suddenly the blinders came off and the whole glory of the fungal kingdom was revealed. What you find is that there is tremendous diversity in how sex determinants are organized and what the sexual cycle entails. There are some fungi that, instead of having just two mating types, they have thousands and thousands of mating types, and this is just mind boggling.

That's one end of the spectrum: you could go from two to thousands. It got us thinking, what if you could you go from two to only one? I had never studied evolution, but I started reading and thinking much more like an evolutionary biologist and in an evolutionary context. I often say that's the sign of a really great institution, if they can take aging faculty members and teach them some completely new area that changes the trajectory of their research. This led to the discovery of unisexual reproduction and its impact on the evolution of eukaryotic microbial pathogens.

JCI: You're clearly someone who allows yourself to be inspired in your research. What inspires you now?

Heitman: I think there are two things that inspire you: one is what you yourself become interested in scientifically, and the second is what the people who are training in your lab are inspired to think about. Part of the reason we've been so open to working on new things is that it is very exciting for the undergraduates, graduate students, and postdoctoral fellows to explore new directions.

One facet of the Korsmeyer Award that is unique is that it is an award both for science and for mentoring. I often tell people that we have two equally important 
missions. The first is to conduct the best science we can, and the second is to train the best scientists that we can train. We advance science through the mentoring and experiences of trainees.

When you start your career you don't really realize how gratifying mentoring will be. You have this idea that the focus is on science and what you will discover, but learn that the personal aspect of mentoring is very deeply fulfilling. On an important level, you represent the one constant in the lab. There's this continual influx of new people with tremendous diversity in background, interests, education, language, and culture. I think that the people who have worked in the lab, as well as the people in the department and on our collaborative teams, have been and continue to be inspirational.

\section{Sarah Jackson}

1. Neill US. A conversation with Michael Hall. JClin Invest. 2017;127(11):3916-3917.

2. Williams CL. Talking TOR: a conversation with Joe Heitman Rao Movva. JCI Insight. 2018;3(4):e99816.

3. Tropschug M, Barthelmess IB, Neupert W.
Sensitivity to cyclosporin A is mediated by cyclophilin in Neurospora crassa and Saccharomyces cerevisiae. Nature. 1989;342(6252):953-955.

4. Mody CH, Toews GB, Lipscomb MF. Cyclosporin A inhibits the growth of Cryptococcus neoformans in a murine model. Infect Immun. 1988;56(1):7-12.

5. Odom A, Muir S, Lim E, Toffaletti DL, Perfect J, Heitman J. Calcineurin is required for virulence of Cryptococcus neoformans. EMBO J. 1997;16(10):2576-2589.

6. Alspaugh JA, Perfect JR, Heitman J. Cryptococcus neoformans mating and virulence are regulated by the G-protein alpha subunit GPA1 and cAMP. Genes Dev. 1997;11(23):3206-3217. 